\title{
Athlete's Mood State before Artistic Gymnastics Competitions
}

\author{
Carlos Eduardo Lopes Verardi' ${ }^{1}$, Vinicius Barroso Hirota ${ }^{2}$, Igor Malinosqui Rinaldi ${ }^{1}$, \\ Marina Pavão Battaglini-Mattos' ${ }^{1}$, Anderson Ricardo Malmonge Barbosa Luciano', \\ Silvia Regina Cassan Bonome Vanzelli' Fernanda Santos Calo Silva1, \\ Talita Fabiana Roque da Silva1, Mayra Grava de Moraes ${ }^{1}$
}

${ }^{1}$ Sao Paulo State University (UNESP), Bauru, Brazil

${ }^{2}$ Faculdade Estácio Unidade Carapicuíba, Carapicuíba, Brazil

Email: mayra-grava@hotmail.com

How to cite this paper: Verardi, C. E. L., Hirota, V. B., Rinaldi, I. M., BattagliniMattos, M. P., Luciano, A. R. M. B., Vanzelli, S. R. C. B., Silva, F. S. C., da Silva, T. F. R., \& de Moraes, M. G. (2018). Athlete's Mood State before Artistic Gymnastics Competitions. Psychology, 9, 2859-2868. https://doi.org/10.4236/psych.2018.914165

Received: November 6, 2018

Accepted: December 17, 2018

Published: December 20, 2018

Copyright $(9) 2018$ by authors and Scientific Research Publishing Inc. This work is licensed under the Creative Commons Attribution International License (CC BY 4.0).

http://creativecommons.org/licenses/by/4.0/

\begin{abstract}
The pre-competition mood is one of the main factors that can influence the performance of an athlete and changes in the athlete's mood may be observed as training becomes more intense because elevated levels of tension, anger and depression increase the likelihood of mental and physical disorders. The hostile negative mood is a predisposing factor for many chronic-degenerative diseases. In this context, the objective of the present study was to evaluate the mood of athletes before artistic gymnastics. The participants were 90 athletes from gymnastics, male $(n=45)$ and female $(n$ $=45$ ), mean age $15.2 \pm 5.23$ years (coefficient of variation of $34.40 \%$ ), assessed by Brunel Mood Scale, adapted by Profile of Mood States (POMS), designed to enable quick measurement of the mood state in adults and adolescents. A portion of the athletes interviewed did not achieve a desirable performance according to the iceberg profile. We observed that the athletes present characteristics of the iceberg profile in the investigated phase. However, of the total of 90 athletes, 64 (71.1\%) were in the standard, and 26 athletes $(28.9 \%)$ did not reach values considered ideal in the force factor, equal or higher than the 60th percentile. In this study, the artistic gymnastics athletes showed the mood profile that favors the performance and health and when analyzing the association between the subjective states of humor and age, we verified that the age did not influence the state of humor.
\end{abstract}

\section{Keywords}

Athletes Mood States, Profile Iceberg Mood, Gymnastics, Sports Competition 


\section{Introduction}

Stress associated with sports racing is a more relevant factor, related to athletes performance, training rigors and demands of competitive contexts (Hanton, Thomas, \& Mellalieu, 2009). Prolonged exposure to certain stressors can have serious negative consequences. Numerous signs and symptoms from excessive training are muscle pain, neuroendocrine and immune changes, changes in mood and constant fatigue (Taylor, 2009).

Changes in the athlete's mood may be observed as training becomes more intense because elevated levels of tension, anger and depression increase the likelihood of mental and physical disorders, resulting in decreased athletic performance associated with injury of health, characterizing the excess of training. The hostile negative mood is a predisposing factor for many chronic-degenerative diseases (Young, 2007). Therefore, Marques \& Brandão (2010) evaluated the association between training volume, athletes' perception of effort and mood states. The results showed significant differences between the week of higher training volume and the week of lower volume. Therefore, these authors emphasize the existence between this association, that when there is an increase in the volume of training, there is also an increase in the perception of effort and fatigue.

Overtraining affects sports performance and mental health, causing mood disorders, associated with high training loads. Consequently, athletes with excessive training have demonstrated an inverted iceberg profile, that is, a drop in disposition accompanied by exacerbated negative states (tension, anger, fatigue) (Weinberg \& Gould, 2014).

The pre-competition mood is one of the main factors that can influence the performance of an athlete (Keikha, Yusof, \& Jourkesh, 2015). Vega Marcos et al. (2014) analyzed the relationship between precompetitive mood states and sports performance in volleyball athletes. The results revealed that when the team lost a match and hence the chance to win a match, athletes' moods were negatively altered, with low levels of tension and stamina, and high levels of depression and fatigue.

Therefore, it is justified to diagnose the symptoms related to mood changes, especially in the moments that precede the sports competition, something that may justify a change in the strategy of competition or even the replacement of an athlete who needs rest. In this context, the objective of the present study was to evaluate the mood of athletes before artistic gymnastics.

\section{Material \& Methods}

Participated in the present study 90 athletes of artistic gymnastics, male $(n=45)$ and female $(n=45)$, with a mean age of $15.2 \pm 5.23$ years (coefficient of variation of $34.40 \%)$, artistic performance of several municipalities of the State of São Paulo/Brazil, in official sports competitions.

Initially, the research project was forwarded to the Research Ethics Committee 
and approved under Process No. 8037/46/01/11. Before the data collection, we requested the permission to develop the research, together with the professionals responsible for the teams, presented the objectives and methodology used during the study.

Athletes and their guardians, through standard instructions and information, were informed about the conditions for joining the research. The condition to participate in the research was the return of the Post-Informed Consent Form duly signed by the parents or guardians. The athletes who met the criteria for the participation of the research were interviewed individually "in loco" during the competitions of artistic gymnastics, between 30 and 60 minutes before the tests.

The instrument used was Brunel Humor Scale (BRUMS): developed to allow faster measurement of the mood state in populations composed by adults and adolescents by Terry, Lane, \& Fogarty (2003). Adapted from the Profile of Mood States (POMS) by Mcnair, Lorr and Droppleman (1971), validated by Rohlfs et al. (2008), having internal consistency values (Cronbach's alpha) of more than 0.70 for all constructs of the scale.

The questionnaire contains 24 simple mood indicators, such as feelings of anger, disposition, nervousness and dissatisfaction perceived by the assessed individual. The participants responded as they feel about such sensations, according to the scale of 5 points (from $0=$ nothing to $4=$ extremely). With the sum of the answers referring to each construct, a score is obtained that varies from 0 to 16 for each state of humor. The form put in the question is "How do you feel now", though another way: "How have you felt this past week, even today," or "How do you normally feel" can be used.

Evaluated six subjective and transient mood states: Tension, Depression, Rage, Vigor, Fatigue, and Mental Confusion. These factors are considered negative factors and vigor classified as a positive factor. The humor profile with a high value of vigor and low values for the other variables is denominated "iceberg profile”, being representative of positive mental health (Morgan et al., 1987).

We organized the data collected in table and figures to facilitate the presentation, providing the best understanding of their items, with analysis of descriptive statistics (mean, median, standard deviation, minimum, maximum) and values of percentile and frequency of absolute and relative occurrence of the answers obtained. A variance analysis (ANOVA) and Student's t-test were performed to compare the means between groups.

In order to demonstrate the internal consistency of the Instrument's questions, the Cronbach's Alpha Coefficient was calculated separately in each factor of the instrument and the total result of the instrument. Pearson's linear correlation coefficient $(r)$ was used to verify if there was a correlation between six subjective and transient mood states. The degree of the correlation coefficient was qualitatively assessed according to the Callegari-Jacques (2007) proposal as follows: weak (between 0.00 and 0.30); regular (between 0.30 and 0.60); strong (between 0.60 and 0.90 ) and very strong (between 0.90 and 1.00). A significance 
level of 0.05 was adopted for all statistical tests. All calculations were made using the SPSS data editor, version 20.0.

\section{Results}

To confirm the reliability of the instrument, we observed a total Alpha result of the instrument of 0.87 . Within each factor, the results were: Tension (0.75); Depression (0.82); Rage (0.87); Vigor (0.63); Fatigue (0.75) and Mental Confusion (0.74).

Table 1 presents the results of the descriptive statistics obtained by the participants in each of the subscales of the mood state of the athletes analyzed moments before the tests in artistic gymnastics competitions. In general, when considering the variation of the score obtained from 0 to 16 , by means of the sum of the responses of each factor, the athletes who participated in the present study had a high mean for the vigor $(11 \pm 3.36)$ and the negative factors like tension $(6$ $\pm 3.40)$, depression $(1 \pm 2.57)$, rage $(3 \pm 3.374)$, fatigue $(4 \pm 2.83)$ and confusion $(3 \pm 2.80)$. However, these results generally show a balance between the positive and negative mood factors evaluated in these athletes.

A Pearson linear correlation test was applied to verify the correlations between the six humor subscales. We also submitted the results to a comparative analysis performed using Student's t-test, and a significance level of $p<0.05$ was adopted (Table 1 ). When analyzing Table 1 it can be observed that there was a strong positive linear correlation and a statistically significant difference $(\mathrm{r}=$ $0.66, p=0.000)$ between depression and rage; depression and confusion $(\mathrm{r}=$ $0.60, p=0.000)$ and tension and confusion $(\mathrm{r}=0.60, p=0.000)$. There was also a moderate positive and statistically significant correlation $(\mathrm{r}=0.55, p=0.001)$ between rage and fatigue, as well as fatigue and mental confusion $(\mathrm{r}=0.47, p=$ 0.006).

For a population of athletes, a percentile value greater than 60 for the force factor is estimated as ideal and less than 40 for negative factors such as anger, fatigue, depression, tension and confusion. We can observe the results found in percentile referring to the humor state profile of the athletes analyzed in Figure 1.

We observed that the athletes present characteristics of the iceberg profile in the investigated phase. Although it was observed in most of the evaluated athletes a behavior corresponding to the iceberg profile, it is observed through the scores obtained in the tension factor (Table 1 and Figure 1) the concern attributed to the performance itself preceding the beginning of the artistic gymnastics' tests.

In the comparative analysis performed with the Student's t-test among the six subscales referring to the mood state (Figure 1 ), it indicated a statistically significant difference $(p<0.05)$ between means of vigor $(p=0.000)$, tension $(p<$ $0.046)$ and depression $(p=0.046)$. There was no significant difference between rabies $(p=0.392)$, fatigue $(p=0.385)$ and confusion $(p=0.455)$. 
However, a portion of the athletes interviewed did not achieve a desirable performance according to the iceberg profile. Of the total of 90 athletes, 64 (71.1\%) were in the standard, and 26 athletes $(28.9 \%)$ did not reach values considered ideal in the force factor, equal or higher than the 60th percentile (Figure 1 and Figure 2).

Figure 3 characterizes the data distribution associated with the six subjective states of humor and the age of the athletes of artistic gymnastics. This analysis shows that there is no strong correlation and it is not possible to explain if the age variation defines the levels of the six subjective mood states (fatigue, confusion, depression, tension, anger and vigor).

Table 1. Pearson's correlation, Student's t-test and descriptive statistics among the six subjective states regarding the athletes' state of artistic gymnastics $(n=90)$.

\begin{tabular}{ccccccc}
\hline & Tension & Depression & Rage & Vigor & Fatigue & Confusion \\
\hline Tension & & & & & & \\
Depression & 0.36 & & & & & \\
Rage & 0.45 & $0.66^{*}$ & & & & \\
Vigor & 0.22 & -0.2 & -0.06 & & & \\
Fadtigue & 0.45 & 0.5 & $0.55^{*}$ & -0.11 & & \\
Confusion & 0.6 & 0.6 & 0.55 & -0.05 & $0.47^{*}$ & \\
Mean & 6 & 1 & 3 & 11 & 4 & 3 \\
SD & 3.4 & 2.57 & 3.74 & 3.36 & 2.83 & 2.8 \\
Median & 5 & 0 & 1 & 11 & 3 & 2 \\
Minimum & 0 & 0 & 0 & 1 & 0 & 0 \\
Maximum & 14 & 14 & 15 & 16 & 14 & 16 \\
\hline
\end{tabular}

*statistically significant difference $(p<0.05)$.

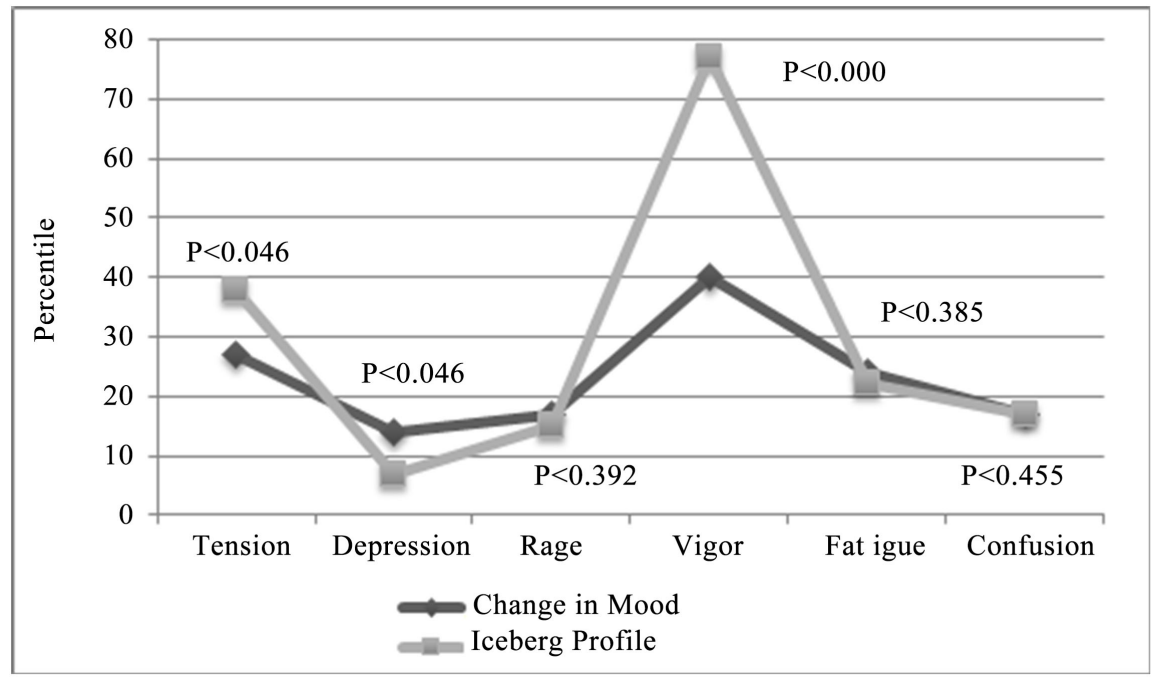

Figure 1. Percentile and Student t-test values for athletes of artistic gymnastics $(n=90)$ presenting the iceberg profile and changes in mood state. 


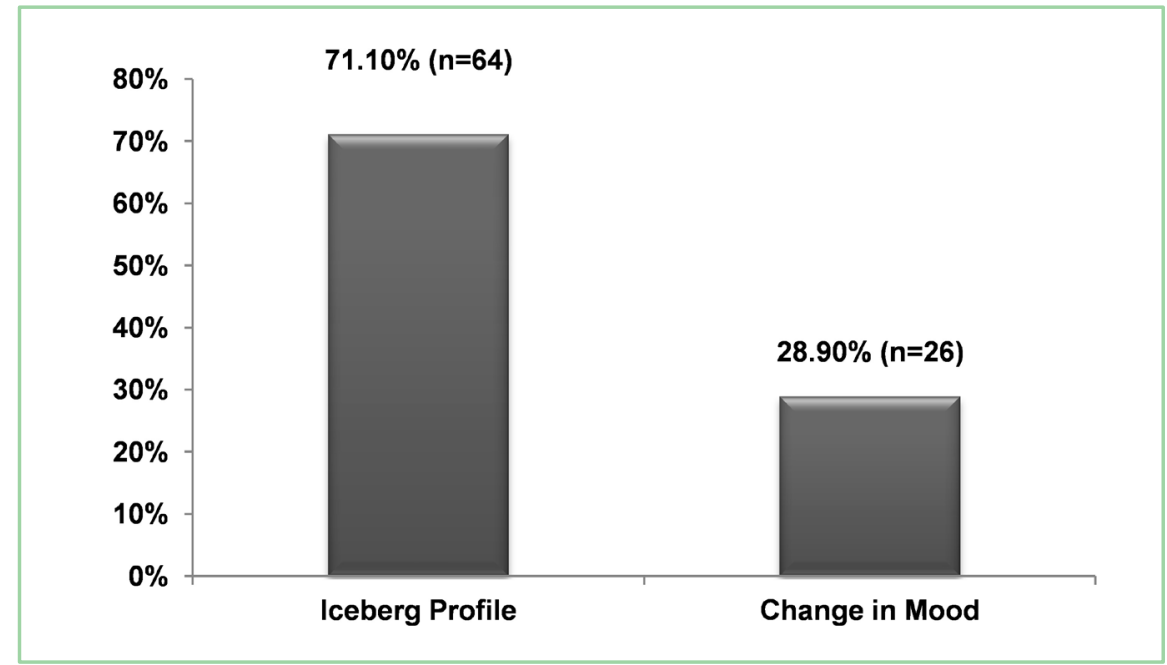

Figure 2. The absolute and relative frequency of occurrence, referring to the iceberg profile and changes in mood state among athletes ofartistic gymnastics.

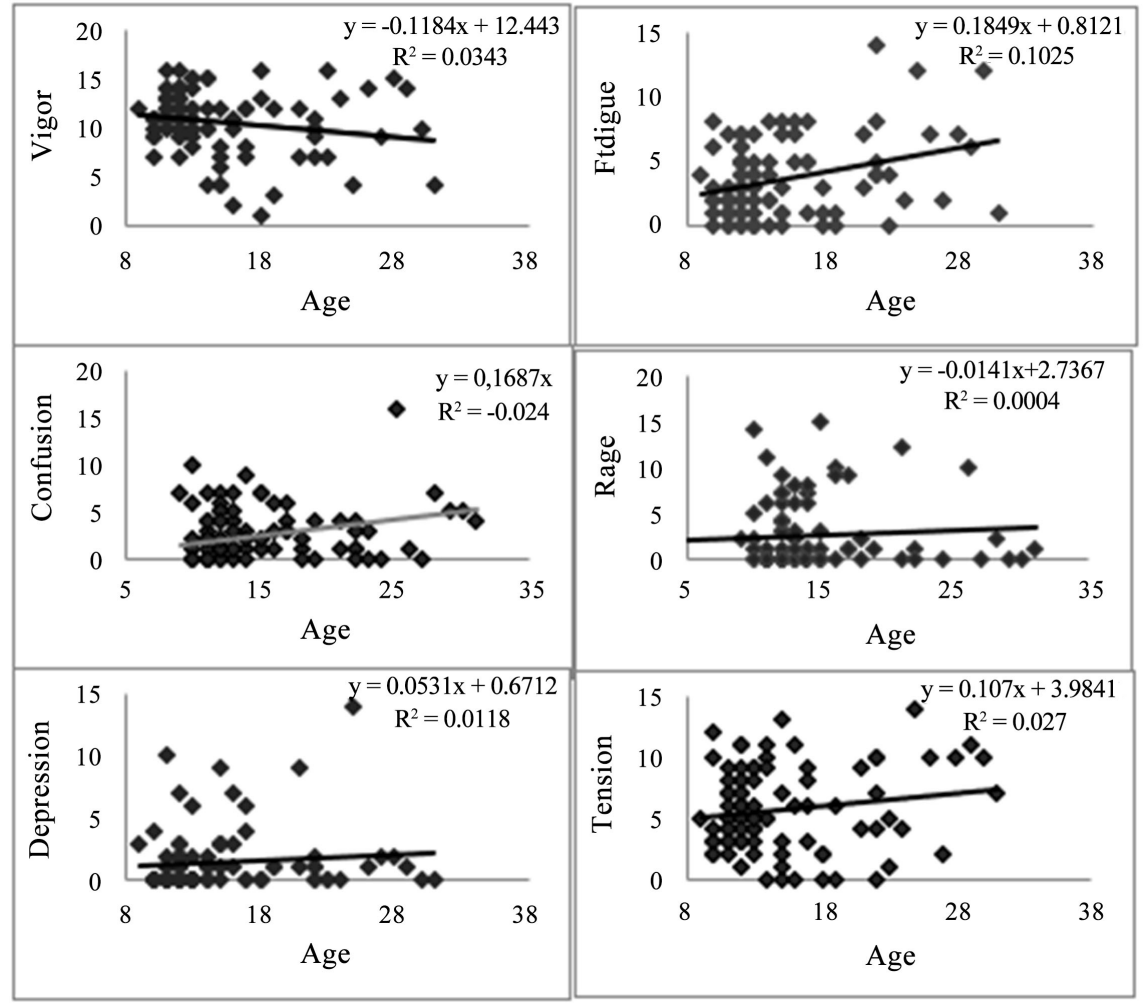

Figure 3. Dispersion of the six subjective states regarding the state of mood by age among athletes of artistic gymnastics $(n=90)$.

\section{Discussion}

It is advisable to control the volume, in the daily intensity of training, as well as in different moments of the sports competition, with the aim of tracing individual profiles of the changes in the athletes' mood (Lane \& Terry, 2000). The purpose of this study was to analyze the iceberg profile before the tests of artistic 
gymnastics, something that may justify, for example, a change in the competition strategy or even the replacement of an athlete in need of rest.

In the present study, the majority of athletes $(71.10 \%)$ presented the characteristics of the iceberg profile in the investigated phase. For most of the interviewed athletes, this is a positive result, since the force factor is directly related to the good sports performance and is directly related to the other mood factors. Athletes who exhibit high levels of vigor before competition are more likely to succeed. One possible explanation is that confident athletes believe in their ability to perform well and win (Keikha et al., 2015). It should be noted that athletes with low pessimism show higher scores in force (Gil et al., 2015).

Especially in the moments that precede the tests of artistic gymnastics this state denominated profile of iceberg is close to the one considered ideal so that the athlete reaches the best sporty performance (Lane \& Terry, 2000; Morgan, Brown, O'Connor, \& Ellickson, 1987; Weinberg \& Gould, 2014).

However, by the results obtained, a portion of the athletes (28.9\%) presented alterations in the subjective mood states. This is a worrying result, since an opposite profile of iceberg, low level of vigor and high scores of negative factors such as fatigue, anger, depression, tension and confusion, characterize a state of depressed mood (Brandt et al., 2010; Lane \& Terry, 2000; Nixdorf et al., 2013). In athletes, high level of fatigue and worsening of mood contribute to the early diagnosis of overtraining syndrome.

Besides, correlation analyzes showed a significant relationship between depression and anger, depression and confusion, and tension with confusion. Although no causality can be assumed based on these results, elevated levels of stress and depression factors may be indicative of discomfort but not necessarily related to sport (Brandt et al., 2011; Sánchez, Romero, \& Ortís, 2013).

Elite athletes experience a variety of stressors that can increase their vulnerability to mental health. Among them, we can highlight the psychological impacts resulting from sports competitions, injuries, changes in mood and burnout. Thus, more epidemiological studies and intervention are required to adopt optimal coping strategies in order to respond to the mental health needs of athletes (Gulliver et al., 2015; Rice et al., 2016). Factors such as chronic stress, coping strategies and level of exhaustion and recovery can be a starting point for the establishment of prevention programs and support interventions for depressed athletes (Nixdorf et al., 2013).

High levels of tension can be useful for sports performance, contributing to energy production and consequently reducing other factors such as fatigue. Especially in artistic gym competitions, high levels of tension increase the likelihood of an athlete getting injured. During the competition, the guidelines should be related to the goals of the athlete, the concentration for the task to be performed and the sense of control of the situation. These aspects can contribute to maintaining the humor at appropriate levels, aiming at a better sporting performance (Brandt et al., 2011).

It is emphasized that the artistic gymnastics is a modality in which the athletes 
initiate early. It is believed that with the early entry in this modality the athlete can benefit from the specialization because their levels of competitive peak usually occur before the maturity (Taylor, 2009). Based on the results, we observed that age does not explain the variation among the six mood states. Despite the limited association, this is a highly relevant data, both for the selection of talents and to assist in the prevention of dropouts and increase adherence to training programs (Nicholls \& Polman, 2007). Knowledge in this area, however, is still limited. Thus, more studies are needed to understand the impact of age on mood.

Despite some limitations, due to the possibility that mood may be influenced by stress factors unrelated to training and recovery (Meeusen, Duclos, \& Foster, 2013), the results obtained offer empirical support in the proposal to monitor the mood state profile in athletes belonging to the artistic gymnastics modality. From this analysis, it becomes an effective means to evaluate the distress associated with overtraining (Rohlfs et al., 2008). It is worth pointing out the applicability of BRUMS as an evaluation tool in Sports Psychology, a context that lacks tools adapted to the sporting reality (Rotta, Rohlfs \& Oliveira, 2014). A better understanding of the diagnosis, monitoring and evaluation of the mood state, especially in the moments that precede the sports competition, will allow the identification of positive psychological strategies, which will allow delineating preventive and intervention programs in the various stages of training of athletes' artistic gymnastics.

\section{Conclusion}

In this study, in the evaluation before the competition, the majority of athletes of artistic gymnastics presented a profile of humor that favors the performance in the sport and the health, that is, the profile of iceberg, presenting higher results for vigor $(11 \pm 3.36)$ and lower levels for negative factors liketension $(6 \pm 3.40)$, depression $(1 \pm 2.57)$, rage $(3 \pm 3.374)$, fatigue $(4 \pm 2.83)$ and confusion $(3 \pm$ 2.80 ). When analyzing the association between the subjective states of humor and age, we verified that the age did not influence the state of humor. These results showed a positive mood indicate some distance from negative mood changes and even greater vulnerability to mood disorders in these athletes. It is essential to monitor athletes' moods before competitions so that there are necessary interventions to avoid and prevent possible disorders in the mental health of these individuals.

\section{Conflicts of Interest}

The authors declare no conflicts of interest regarding the publication of this paper.

\section{References}

Brandt, R., da Silveira Viana, M., Segato, L., Leal Kretzer, F., de Carvalho, T., \& Andrade, A. (2011). Relações entre os estados de humor e o desempenho esportivo de velejadores 
de alto nível. [Relationships between Mood States and Sport Performance in High Level Sailors.]. Psicologia: Teoria e Prática, 13, 117-130.

Brandt, R., Viana, M. D. S., Segato, L., \& Andrade, A. (2010). Estados de humor de velejadores durante o Pré-Panamericano. Motriz, 16, 834-840. https://doi.org/10.5016/1980-6574.2010v16n4p834

Callegari-Jacques, S. M. (2007). Bioestatística: Princípios e aplicações. Artmed Editora.

Gil, R. B., Montero, F. O., de los Fayos, E. J. G., Lòpez Gullòn, J. M., \& Pinto, A. (2015). Otimismo, burnout e estados de humor em desportos de competição. Analise Psicologica, 33, 221-233. https://doi.org/10.14417/ap.1019

Gulliver, A., Griffiths, K. M., Mackinnon, A., Batterham, P. J., \& Stanimirovic, R. (2015). The Mental Health of Australian Elite Athletes. Journal of Science and Medicine in Sport, 18, 255-261. https://doi.org/10.1016/j.jsams.2014.04.006

Hanton, S., Thomas, O., \& Mellalieu, S. D. (2009). Management of Competitive Stress in Elite Sport. Sport Psychology, 30-42. https://doi.org/10.1002/9781444303650.ch4

Keikha, B. M., Yusof, S., \& Jourkesh, M. (2015). The Relationship between Pre-Competition State Anxiety Components and Mood State Sub-Scales Scores and the Result of among College Athletes through Temporal Patterning. International Journal of Sport Science, 5, 8-15.

Lane, A. M., \& Terry, P. C. (2000). The Nature of Mood: Development of a Theoretical Model. Journal of Applied Sport Psychology, 12, 16-33. https://doi.org/10.1080/10413200008404211

Marques, L. E., \& Brandão, M. R. F. (2010). Volume de treinamento, percepção subjetiva do esforço e estados de humor durante um macrociclo de treina. Revista Brasileira de Psicologia Do Esporte, 3, 63-78.

http://pepsic.bvsalud.org/scielo.php?script=sci_arttext\&pid=S1981-9145201000010000 5\&lng=es\&nrm=iso\&tlng=pt

Mcnair, D. M., Lorr, M., \& Droppleman, L. F. (1971). Manual for the Profile of Mood States. San Diego CA: Educational and Industrial Testing Services.

Meeusen, R., Duclos, M., \& Foster, C. (2013). Treatment of the Overtraining Syndrome: Joint Consensus Statement of the European College of Sport Science (ECSS) and the American College of Sports Medicine. European Journal of Sport Science, 1-24. https://doi.org/10.1080/17461391.2012.730061

Morgan, W. P., Brown, D. R., O’Connor, M. S., \& Ellickson, K. A. (1987). Psychological Monitoring of Overtraining and Stalennes. British Journal of Sports Medicine, 21, 107-114. https://doi.org/10.1136/bjsm.21.3.107

Nicholls, A. R., \& Polman, R. C. J. (2007). Coping in Sport: A Systematic Review. Journal of Sports Sciences, 25, 11-31. https://doi.org/10.1080/02640410600630654

Nixdorf, I., Hautzinger, M., Beckmann, J. J. J., Frank, R., Hautzinger, M., Beckmann, J. J. J., Beckmann, J. J. J. et al. (2013). Prevalence of Depressive Symptoms and Correlating Variables among German El...: EBSCOhost. Journal of Clinical Sport Psychology, 7, 313-326. https://doi.org/10.1123/jcsp.7.4.313

Rice, S. M., Purcell, R., De Silva, S., Mawren, D., McGorry, P. D., \& Parker, A. G. (2016). The Mental Health of Elite Athletes: A Narrative Systematic Review. Sports Medicine, 46, 1333-1353. https://doi.org/10.1007/s40279-016-0492-2

Rohlfs, I. C. P. de M., Rotta, T. M., Luft, C. D. B., Andrade, A., Krebs, R. J., \& Carvalho, T. de (2008). A Escala de Humor de Brunel (Brums): Instrumento para detecção precoce da síndrome do excesso de treinamento. Revista Brasileira de Medicina Do Esporte, 14, 176-181. https://doi.org/10.1590/S1517-86922008000300003 
Rotta, T. M., Rohlfs, I. C. P. M., \& Oliveira, W. F. (2014). Aplicabilidade do Brums: Estados de humor em atletas de voleibol e tênis no alto rendimento. The Revista Brasileira de Medicina do Esporte, 20, 424-428.

Sánchez, J. M., Romero, E. P., \& Ortís, L. C. (2013). Heart Rate Variability and Psychophysiological Profiles in High-Performance Team Sports. Revista de Psicología Del Deporte, 22, 345-352.

http://ezproxy.library.ubc.ca/login?url=http://search.ebscohost.com/login.aspx?direct= true\&db=psyh\&AN=2013-34421-005\&login.asp\&site=ehost-live\&scope=site\%0Ahttp:/ /Jordi.Moreno.Sanchez@uab.cat

Taylor, S. (2009). Health Psychology (7th ed.). Boston.

Terry, P. C., Lane, A. M., \& Fogarty, G. J. (2003). Construct Validity of the Profile of Mood States-Adolescents for Use with Adults. Psychology of Sport and Exercise, 4, 125-139. https://doi.org/10.1016/S1469-0292(01)00035-8

Vega Marcos, R., Ruiz-Barquin, R., Tejero-Gonzalez, C., \& Rivera-Rodriguez, M. (2014). Relationship between Mood States and Performance in Elite Male Volleyball. Revista de Psicología Del Deporte, 23, 49-56.

http://search.ebscohost.com/login.aspx?direct=true\&db=psyh\&AN=2014-06721-006\&l ang=es\&site $=$ ehost-live

Weinberg, R. S., \& Gould, D. (2014). Foundations os Sport and Exercise Psychology (6E ed.). Human Kinects.

Young, S. N. (2007). How to Increase Serotonin in the Human Brain without Drugs. Journal of Psychiatry \& Neuroscience: JPN, 32, 394-399. 